\title{
Satisfaction, discomfort, obligations, and concerns in population-based breast cancer screening: cross-sectional study in a Danish population
}

Pernille Gabel $^{1 *}$ (D), Mette Bach Larsen ${ }^{1}$, Pernille Bjørnholt Nielsen², Dorte Brandt Svendstrup ${ }^{2}$ and Berit Andersen ${ }^{1}$

\begin{abstract}
Background: Potential barriers to breast cancer screening adherence include patient satisfaction, as well as pain, feeling obliged to participate, and other concerns that might compromise the level of satisfaction.

The present study aimed to assess the overall satisfaction of Danish citizens with their breast cancer screening experiences, as well as their level of discomfort, concerns, and feelings of obligation to participate. Furthermore, we analyzed the associations between overall satisfaction and the remaining outcomes.

Methods: Questionnaires were mailed to 3000 women in the Central Denmark Region who received screening examination results in the fall of 2013. The questionnaire assessed satisfaction (overall, telephone hot-line, and web-based self-service), discomfort (pain and boundaries of modesty), concerns (at invitation, while waiting for results, and after receiving results), and feelings of obligation to participate. Background information was retrieved from Statistics Denmark.

Pearson's chi-square test was used to test differences in outcomes and demographic characteristic distributions between respondents and non-respondents and highly satisfied vs. less satisfied participants. Prevalence ratios (PR) with 95\% Cl were assessed using Poisson regression with robust variance, to estimate associations between satisfaction and the remaining outcomes.
\end{abstract}

Results: Among the participants, $70.3 \%$ and $29.4 \%$, respectively, reported really good and good impressions of the screening program. Lower satisfaction was associated with feeling pain (prevalence ratio (PR), 0.82), feeling that modesty boundaries were transgressed (PR, 0.79), experiencing screening-induced concerns (PR, 0.84), and feeling obliged to participate (PR, 0.96). Of the participants, $36.2 \%$ and $12.9 \%$, respectively, felt very much and moderately obliged to participate. A total of $72.6 \%$ reported no screening-induced concerns, including $73.3 \%$ of those with negative screening results and $38.1 \%$ of those with positive screening results.

Conclusions: Overall satisfaction with breast cancer screening was very high, but discomfort, feelings of obligation, and concerns were associated with lower satisfaction levels. A continuing focus on high service in breast cancer screening is important for achieving the highest benefit from the program. This includes initiatives to employ the least painful techniques, to respect the patients' modesty as much as possible, and to deliver fast screening results and thus minimize concerns among women awaiting results.

Keywords: Breast neoplasms, Early detection of cancer, Patient satisfaction, Mass screening, Cross-sectional studies

\footnotetext{
*Correspondence: pergab@rm.dk

'Department of Public Health Programmes, Regional Hospital Randers,

Skovlyvej 15, DK-8930 Randers NØ, Denmark

Full list of author information is available at the end of the article
} 


\section{Background}

Among women worldwide, breast cancer is the most prevalent cancer and the leading cause of cancer-related death [1]. Early breast cancer diagnosis and optimal treatment can reduce mortality [2]. Breast cancer screening aims to detect the disease at an early stage to improve prognosis, and can reportedly lead to a $15-20 \%$ reduction in breast cancer mortality [3, 4]. Therefore, many Western countries have introduced population-based breast cancer screening programs [5], although there remains debate regarding the benefits and harms $[6,7]$.

To achieve mortality reduction with breast cancer screening, the targeted population must adhere to the screening guidelines [8]. Several factors are reportedly associated with following recommendations for repeated mammographie$\mathrm{s}$-including satisfaction with clinic service and/or healthcare providers (e.g., communication and accessibility), low physical discomfort (e.g., experiencing pain), and low psychological distress (e.g., experiencing concerns or embarrassment) $[9,10]$.

Since 2008, under Danish law, all Danish women of 50-69 years of age have been offered biennial breast cancer screening free of charge [11]. The participation rate in the Danish national breast cancer screening program reached $84.3 \%$ in $2012-2013$ [12]. In order to maintain this high participation rate, it is important to ensure continuing good user experiences in the screening program.

It has been hypothesized by Ploug et al. that the Danish breast cancer screening program is organized in a manner that makes women feel obliged to participate, which is in opposition to the right of free choice [13]. However, this implied obligation to participate has never been examined within the Danish breast cancer screening program.

The present study aimed to assess the overall satisfaction with breast cancer screening in a Danish population, including specific assessment of the level of discomfort, concerns, and feelings of obligation to participate. We further intended to analyze associations between overall satisfaction and demographic characteristics, discomfort, concerns, and feelings of being obligated to participate.

\section{Methods}

\section{Study design and setting}

We designed a cross-sectional study using survey and register data. In accordance with Danish law, the study was approved by the Danish Data Protection Agency (Journal Number: 2007-58-0010/Case number: 1-16-02-423-13).

This study was performed in the Central Denmark Region (CDR), which comprises both rural and urban areas, and includes the city of Aarhus, the second largest city in Denmark. The CDR has approximately 1.3 million residents (October 1, 2013) corresponding to approximately $23 \%$ of the total Danish population. These residents included 159,726 women 50-69 years of age [14].

The invitation to participate in breast cancer screening includes a scheduled appointment for a screening mammography at one of five screening units in the CDR. To unsubscribe from the program or change their appointment, women can contact the Department of Public Health Programmes by telephone or e-mail, or by using a web-based self-service. If a woman does not attend the scheduled screening, she will receive one reminder without another pre-booked appointment. Information about the screening program is available in an information booklet. The booklet is available online, and is also sent to the women once with their first invitation to screening. The booklet contains information on breast cancer, breast cancer screening, and advantages and disadvantages of screening participation.

One of the five screening units is situated at a hospital, and the other four are located outside of the hospital, for example, in a shopping or healthcare center. Participants' average distance to the chosen screening unit is $23.2 \mathrm{~km}$ (range, 0-118.3 km) [15]. Mammographies are performed by specially trained healthcare assistants. The process is streamlined to enable assistants to screen 1012 women per hour at each mammomat. Two images are taken of each breast (cranio-caudal and mediolateral oblique), which are later independently evaluated by two screening radiologists [11].

Women receive their screening results within 2 weeks. If evaluation of the screening images cannot rule out cancer, an appointment is scheduled for further diagnostic procedures at the nearest hospital within six calendar days from the date the results are released. If the screening reveals no sign of cancer, the woman is informed that she will be invited again in 2 years if still within the screening age range, and that she should seek medical advice in the event of any breast cancer symptoms regardless of the time since last screening mammography. The women's general practitioners are simultaneously informed of the screening results.

\section{Participants}

Women in the CDR who received breast cancer screening results during weeks 42 to 49 of 2013 were eligible for inclusion in this study. All Danish residents are listed in the daily updated Civil Registration System, which includes unique civil registration numbers (CRNs), names, and postal addresses [16], and is linked to the CDR's administrative breast cancer screening system. From the administrative system, eligible women were identified once every 2 weeks, and the study included a random sample of 150 women from each screening unit. Women were randomly selected using the RAND-function in 
Microsoft Office Excel (2003 version): after assigning the women a random number between 0 and 1 , the women were ordered according to the random numbers. The first 150 women from each screening unit were chosen to receive a questionnaire.

The included women were sent a questionnaire along with a description of the survey. Women were asked to fill out a questionnaire on their experiences in their recent breast cancer screening participation for quality assurance purposes. Hence the women received the questionnaire and survey invitation within 9 days after they received their screening results. Participating women could complete the questionnaire and return it to the study office by ordinary mail in a pre-addressed pre-stamped envelope, or they could complete it online using a unique code provided in the accompanying letter. No reminders were issued. Women were included in the study if they returned the questionnaire no later than December 23, 2013 (Fig. 1).

\section{Questionnaire content and development}

The questionnaire was in Danish, and was a revised and extended version of a standard questionnaire that is regularly used for quality assurance in hospital departments in Denmark [17]. It comprised standard questions regarding satisfaction, supplemented with questions relating to discomfort, feelings of obligations, and concerns specific to the breast cancer screening procedure (Additional file 1).

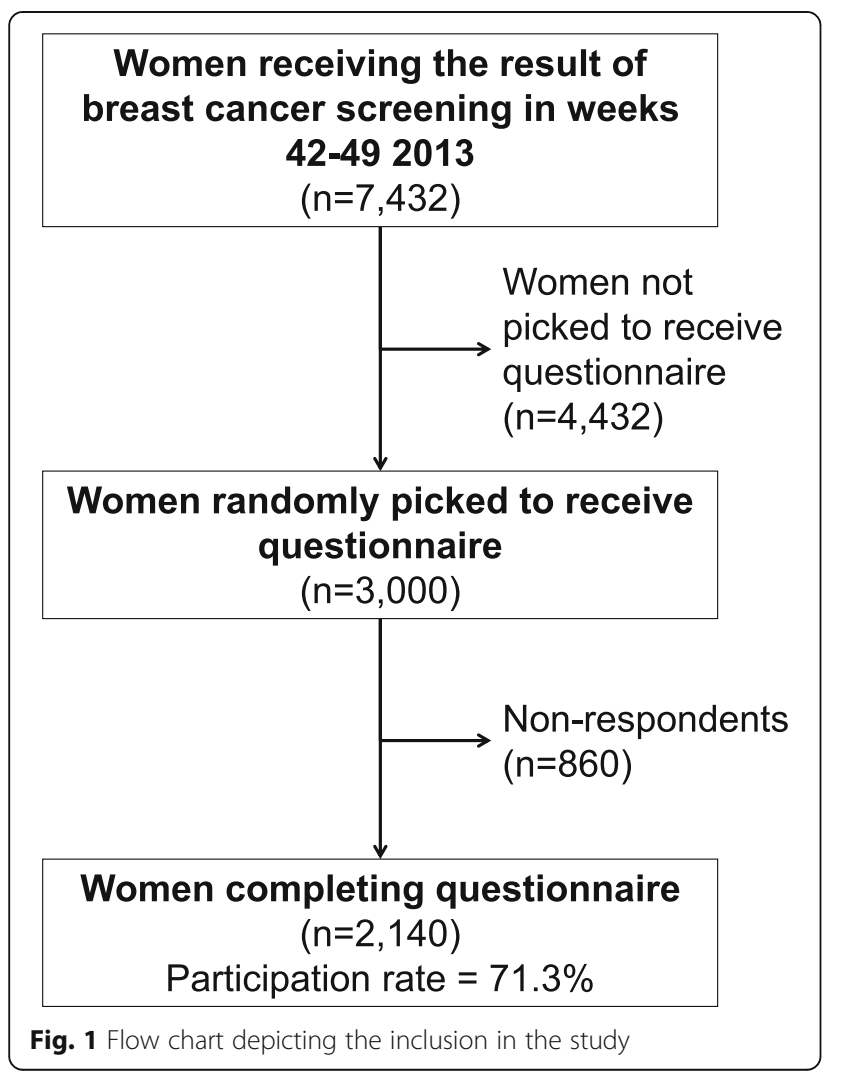

The questions were tested in the target population at a regional screening unit-first in 2010, when the questions on satisfaction and discomfort were initially tested in 19 selected women, and next in 2013, when the questions on obligations and concerns were added and tested in a group of 10 women. Participants were asked to complete the questionnaire, and were then individually interviewed about their understanding of the questions and their relevance. Both procedures were conducted using semi structured interviews, and resulted in the identification of minor misunderstandings, that prompted corrections in the questionnaire. The final questionnaire included a total of 50 items on different aspects of satisfaction in regards to service quality, expectations, program logistics, parking facilities, waiting times etc. A total of 10 items were used for analyses in the present study. These 10 items are described in the Data section.

\section{Data}

The presently analyzed data included information from the screening program's administrative system in the CDR, registry data from Statistics Denmark, and survey data. Age at the time of receiving the screening result was retrieved from the administrative system, and was categorized into four groups: 50-54, 55-59, 60-64, and 65-69 years of age. Demographic data were collected from Statistics Denmark [18]. Ethnicity was classified as Danish, immigrant from western countries, or immigrant from non-western countries utilizing definitions provided by Statistics Denmark. Educational level was classified as low ( $\leq 10$ years), medium (10-15 years), or high (>15 years) according to the UNESCO classification of education [19]. Marital status was recorded as married/cohabitating or single.

Overall impression is a global item covering the women's feelings about the screening program. Impressions are thought to cover both expected and percieved quality of the program, and according to Mohamed et al., perceived quality is related to patient satisfaction [20]. Thus, in our study satisfaction with breast cancer screening was assessed based on three questionnaire items: "What was your overall impression of the entire mammography screening process (from receiving the invitation until response letter was received)?" (item 41), "What was your overall impression of the service offered by phone?" (item 25), and "What was your overall impression of the self-service facility offered?" (item 15). Only the first item was used to analyze associations.

Very few respondents gave low scores on the item on overall impression of the screening process (satisfaction) (Table 2). Thus, for our analyses, the response "Excellent" was coded as highly satisfied and the remaining three categories ("Fine", "Poor", and "Really poor") were coded as less satisfied. This approach was applied in a previous study that reported a similarly high level of satisfaction [21]. 
Discomfort was assessed by two questionnaire items: "Did you feel that your limits of modesty were exceeded during the examination?" (item 33) and "Did you feel any pain during the examination?" (item 34). For both items, the answers were coded as yes for responses of "To a great extent" or "To some extent", and no for responses of "To a minor extent" or "Not at all".

Based on literature research, a conceptual framework for perceived obligations in the health care system was adapted from Sider et al. [22]. It is based on the assumption that some citizens feel a moral obligation towards accepting the health preserving offers provided by the health care system. The moral obligation consists of three factors; (1) a moral obligation to preserve ones own health (instinctive obligation in order to stay alive), (2) a moral obligation to keep healthy for the sake of others (everyone has loved ones, and as such are important in the lives of others), and (3) a moral obligation to maintain healthy as a member of the human community (a mutual expectation of life-preserving behavior is expected in a human society) (Fig. 2).

Feelings of obligation were assessed by one global questionnaire item: "Did you feel obliged to participate in the mammography screening?" (item 6). Answers to this item were coded in the same manner as the responses for discomfort. Reasons for feeling obliged to participate (item 7) were coded as own expectations ("the opportunity to have an eventual early detection of breast cancer in order to initiate treatment" or "I have participated in previous screenings"), family/friends' expectations ("Friends/family expected me to participate"), organizational aspects ("To receive an invitation without having requested it", "To receive a pre-scheduled date/time for mammography screening", "The invitation appeared as a scheduled call for screening", or "Central Denmark Region is mentioned as sender of the invitation"), and other reasons ("Other").

Screening-induced concerns were assessed by three questionnaire items concerning the three main stages in screening participation (before, during and after). Responses to "Did you have any concerns when receiving the invitation?" (item 8) and "Did you feel any concern about the screening result from the time of screening until the result of screening was received?" (item 35 ) were coded in the same manner as the responses for discomfort. Responses to "After having attended the mammography screening do you experience an increased worry for developing breast cancer than before?" (item 42) were coded as yes if the respondent answered "More worried" or no if the respondent answered "Nothing has changed" or "Less worried". The three variables were combined into one category labeled screening-induced concerns, which was coded as no if all three questions were coded "no" or as yes if at least one of the three questions was coded as "yes".

\section{Statistics}

All statistical analyses were carried out in Stata/SE 14 (STATACorp LP, College Station, Texas, USA). Pearson's chi-square test was used to test differences in demographic characteristic distribution between respondents and non-respondents. Test for difference in mean age between respondents and non-respondents were tested using a student's t-test. Distributions of responses to the survey items on satisfaction, discomfort, obligations, and screening-induced concerns were calculated as proportions with 95\% confidence intervals (95\% CI). Proportions were used to estimate the level of screeninginduced concerns among women participating in breast cancer screening. Pearson's chi-square test was used to

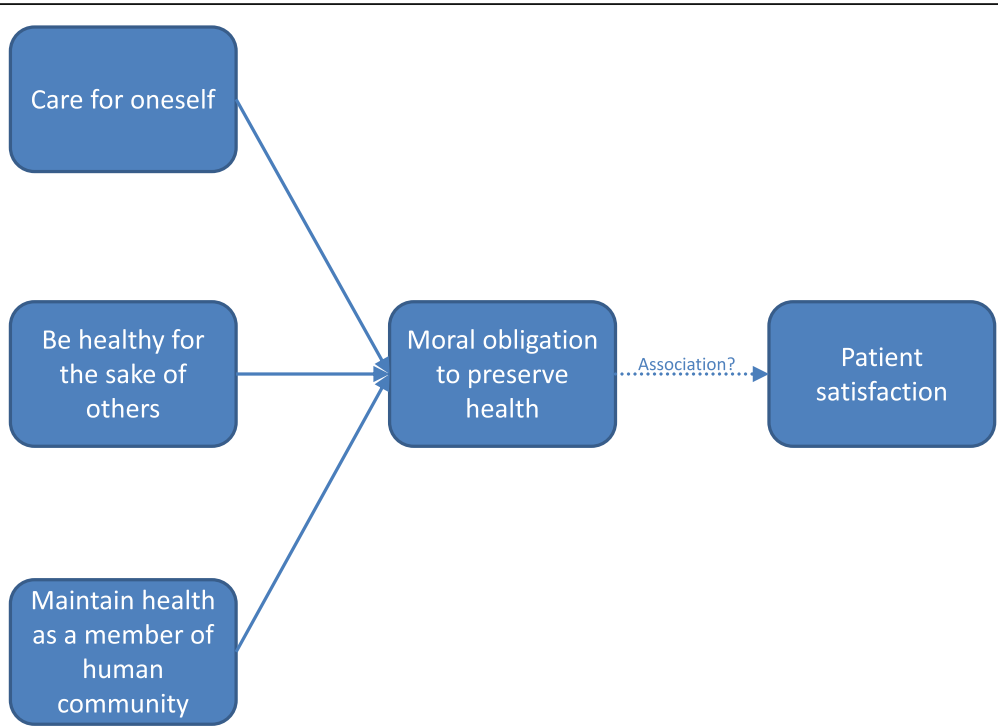

Fig. 2 Obligations framework. Adapted from Sider et al. [22] 
test for differences in proportions between women with negative vs. positive screening results.

Prevalence ratios (PR) with 95\% CI were used to evaluate how satisfaction was associated with demographic characteristics, feelings of obligation to participate, discomfort, and concerns. PR was assessed using Poisson regression with robust variance to adjust for clustering between screening units. The same association measures were used to conduct sensitivity analyses omitting the women with positive screening results. The proportion of satisfied women exceeded $20 \%$. In cross-sectional studies, logistic regression is frequently used to estimate an odds ratio (OR) as an association measure equivalent to the relative risk (RR). However, when the proportion experiencing an outcome exceeds $20 \%$, an OR overestimates the RR, and the PR is a more accurate measure of association $[23,24]$.

\section{Power calculations}

Power calculations were performed based on a 5\% significance level and an $80 \%$ statistical power. To detect a difference of $72.2 \%$ vs. $81.6 \%$ in the proportions of satisfied participants between those reporting pain vs. those reporting no pain [21], we had to include at least 600 women in our study. Since there are five screening units and we expected to run cluster analyses, we had to include 3000 women in our study.

\section{Results}

A total of 7432 women were eligible for study inclusion. Of the 3000 women randomly included, 2140 women (71.3\%) completed the questionnaire (Fig. 1). Compared to non-respondents, respondents were more likely to be older, ethnic Danes, and married/cohabitating. Screening results did not differ between respondents and nonrespondents (Table 1).

\section{Overall satisfaction, discomfort, and obligations}

Among the respondents, $70.3 \%$ had an excellent overall impression of the screening program and $29.4 \%$ had a fine overall impression. The telephone hot-line was rated as excellent by $79.3 \%$ of those who used it, and the web-based self-service was rated as excellent by $72.1 \%$ of the women who used it (Table 2). Among the respondents, 6.8\% reported experiencing discomfort because their limits of modesty were exceeded to some or a great extent during the examination, and $17.9 \%$ reported feeling pain to some or a great extent during the examination (Table 2). A total of $36.2 \%$ of the participants reported feeling obliged to a great extent to participate in screening (Table 2). The predominantly stated reasons for feeling obliged to a great extent were in the categories of own expectations (32.8\%) and organizational aspects (18.4\%) (Table 2).
Table 1 Demographic characteristics and screening result of survey respondents and non-respondents in the survey

\begin{tabular}{llll}
\hline & $\begin{array}{l}\text { Respondents } \\
(n=2140) \\
n(\%)\end{array}$ & $\begin{array}{l}\text { Non-respondents } \\
(n=860) \\
n(\%)\end{array}$ & $\begin{array}{l}\text { P-value } \\
\text { (Chi2) }\end{array}$ \\
\hline Age & 59.7 & 58.3 & $<0.00 \mathbf{1}^{\text {a }}$ \\
Mean & $532(24.9)$ & $264(30.7)$ & $<\mathbf{0 . 0 0 1}$ \\
50-54 & $514(24.0)$ & $243(28.3)$ & \\
55-59 & $512(23.9)$ & $193(22.4)$ & \\
60-64 & $582(27.2)$ & $160(18.6)$ & \\
65-69 & & & \\
Ethnicity & $2079(97.2)$ & $805(93.8)$ & \\
Danish & $30(1.4)$ & $14(1.6)$ & \\
Immigrant (Western \\
country)
\end{tabular}

Numbers in bold indicate statistically significant differences between respondents and non-respondents

${ }^{\text {a }}$ Student's t-test for difference in means

\section{Screening-induced concerns}

Among the respondents, $72.6 \%$ reported no screeninginduced concerns, including $73.3 \%$ of the women with negative screening results and $38.1 \%$ of women with positive screening results. Some women reported experiencing concerns both when receiving the invitation and while waiting for the results, and were more concerned about breast cancer after their screening-including $0.8 \%$ of women with negative screening results and $11.9 \%$ of women with positive screening results (Table 3). The largest proportions of women reported concerns while awaiting their results: $24.1 \%$ of those with negative screening results, $50.0 \%$ of those with positive screening results; $(p<.001)$.

\section{Factors associated with satisfaction}

Analyses of associations between satisfaction with the screening program and demographic characteristics revealed that compared to women of 50-54 years of age older women showed slightly lower satisfaction: adjusted $\mathrm{PR}_{55-59}, 0.94$ (95\% CI, 0.90-0.99); adjusted $\mathrm{PR}_{60-64}, 0.92$ (95\% CI, 0.87-0.97); adjusted $\mathrm{PR}_{65-70}, 0.94$ (95\% CI, 
Table 2 Satisfaction, feeling obliged to participate, being concerned and feeling pain during the examination

\begin{tabular}{|c|c|c|c|c|}
\hline \multirow[t]{2}{*}{ Satisfaction } & Excellent & Fine & Poor & Really poor \\
\hline & $\%(\mathrm{Cl})$ & $\%(\mathrm{Cl})$ & $\%(\mathrm{Cl})$ & $\%(\mathrm{Cl})$ \\
\hline $\begin{array}{l}\text { What was your overall impression of the entire } \\
\text { screening process? }(n=2110)\end{array}$ & $70.3(68.3-72.2)$ & $29.4(27.5-31.4)$ & $0.2(0.1-0.5)$ & $0.1(0.0-0.4)$ \\
\hline $\begin{array}{l}\text { What was your overall impression of the service } \\
\text { offered by phone? }(n=464)\end{array}$ & $79.3(75.4-82.7)$ & $20.5(17.0-24.4)$ & 0.0 & $0.2(0.0-1.5)$ \\
\hline $\begin{array}{l}\text { What was your overall impression of the self-service } \\
\text { facility offered? }(n=412)\end{array}$ & $72.1(67.5-76.2)$ & $24.8(20.8-29.2)$ & $1.9(1.0-3.8)$ & $1.2(0.5-2.9)$ \\
\hline Feeling discomfort & To a great extent & To some extent & To a minor extent & Not at all \\
\hline $\begin{array}{l}\text { Did you feel that your limits of modesty were } \\
\text { exceeded...? }(n=2115)\end{array}$ & $3.2(2.5-4.0)$ & $3.6(2.9-4.5)$ & $6.1(5.1-7.2)$ & $87.2(85.7-88.5)$ \\
\hline $\begin{array}{l}\text { Did you feel any pain during the examination? } \\
(n=2129)\end{array}$ & $3.4(2.7-4.3)$ & $14.5(13.1-16.1)$ & $44.0(41.9-46.1)$ & $38.1(36.1-40.2)$ \\
\hline \multicolumn{5}{|l|}{ Feeling concerns } \\
\hline $\begin{array}{l}\text { Did you have any concerns when receiving the } \\
\text { invitation? }(n=2113)\end{array}$ & $1.1(0.8-1.7)$ & $8.6(7.5-9.9)$ & $17.2(15.6-18.8)$ & $73.1(71.1-74.9)$ \\
\hline \multirow{2}{*}{$\begin{array}{l}\text { Did you feel any concern about the screening } \\
\text { result from the time of screening until the result } \\
\text { of screening was received? }(n=2117)\end{array}$} & $4.9(4.1-5.9)$ & $20.0(18.3-21.7)$ & $41.0(39.0-43.2)$ & $34.1(32.1-36.1)$ \\
\hline & More worried & Nothing has changed & Less worried & \\
\hline $\begin{array}{l}\text { After having attended the mammography } \\
\text { screening do you experience an increased worry } \\
\text { for developing breast cancer than before? } \\
(n=2128)\end{array}$ & $2.5(1.9-3.3)$ & $73.0(71.1-74.8)$ & $24.5(22.7-26.4)$ & \\
\hline Feeling obliged & To a great extent & To some extent & To a minor extent & Not at all \\
\hline $\begin{array}{l}\text { Did you feel obliged to participate in the } \\
\text { mammography screening? }(n=2087)\end{array}$ & $36.2(34.2-38.3)$ & $12.9(11.5-14.4)$ & $4.4(3.6-5.3)$ & $46.5(44.4-48.7)$ \\
\hline \multicolumn{5}{|l|}{ Reasons for feeling obliged $(n=1116)^{a}$ : } \\
\hline Own expectations ${ }^{\mathrm{b}}$ & $32.8(30.8-34.9)$ & $10.3(9.1-11.7)$ & $3.3(2.6-4.2)$ & No data \\
\hline Family/friends expectations ${ }^{b}$ & $5.6(4.7-6.6)$ & $2.2(1.7-2.9)$ & $0.5(0.3-0.9)$ & No data \\
\hline Organizational aspects ${ }^{\mathrm{b}}$ & $18.4(16.7-20.1)$ & $5.7(4.8-6.8)$ & $1.4(1.0-2.0)$ & No data \\
\hline Other $^{\mathrm{b}}(n=63)$ & $2.1(1.6-2.8)$ & $0.5(0.3-0.9)$ & $0.3(0.2-0.7)$ & No data \\
\hline
\end{tabular}

a Own expectations: Answers "The opportunity to have an eventual early detection of breast cancer in order to initiate treatment" or "I have participated in previous screenings"; Family/friends expectations: Answers: "Friends/family expected me to participate"; Organizational aspects: Answers "To receive an invitation without having requested it", "To receive a pre-scheduled date/time for mammography screening", "The invitation appeared as a scheduled call for screening" or "Central Denmark Region is mentioned as sender of the invitation"; Other: Answers "Other"

${ }^{\mathrm{b}}$ Proportion of respondents reporting feeling obligated to participated due to own expectations, organizational aspects, family/friends expectations or other out of all respondents $(n=2087)$

0.86-1.04). Additionally, immigrants from non-western countries showed lower satisfaction than ethnic Danes: adjusted PR, 0.75 (95\% CI, 0.58-0.97) (Table 4). Overall, women who experienced discomfort showed lower satisfaction. Women who experienced pain showed lower satisfaction than women without pain: adjusted PR, 0.82 (95\% CI, 0.74-0.91). Likewise, women who felt that their limits of modesty were transgressed during the examination were less satisfied than women who did not have this experience: adjusted PR, 0.79 (95\% CI, 0.71-0.88). Similarly, women who felt obliged to participate reported lower satisfaction than women without that feeling: adjusted PR, 0.96 (95\% CI, 0.92-0.99). Being concerned at any time during the screening process was also associated with lower satisfaction (PR, 0.84; 95\% CI,
0.77-0.91), whereas screening result was not associated with satisfaction (Table 4).

\section{Discussion}

\section{Main findings}

The results of this cross-sectional study revealed that almost all participants were satisfied with the breast cancer screening program. However, satisfaction was lower among women who felt discomfort during the screening examination, felt obliged to participate, or experienced screeninginduced concerns. Lower satisfaction was also reported by older women, non-western immigrants, and women with low education levels.

The level of satisfaction was not influenced by screening results. Women with positive screening results generally 
Table 3 Screening induced concerns in women participating in breast cancer screening

\begin{tabular}{|c|c|c|c|}
\hline & All $(n=2083)$ & Neg. screening $(n=2041)$ & Pos. screening $(n=42)$ \\
\hline & $\%(95 \% \mathrm{Cl})$ & $\%(95 \% \mathrm{Cl})$ & $\%(95 \% \mathrm{Cl})$ \\
\hline Reported no screening induced concerns ${ }^{a}$ & $72.6(70.6-74.5)$ & $73.3(71.3-75.2)$ & $38.1(24.3-54.1)$ \\
\hline Concerns induced "only" at one point & $18.8(17.2-20.6)$ & $18.4(16.8-20.2)$ & $40.5(26.3-56.4)$ \\
\hline At the receiving of the invitation & $1.9(1.4-2.6)$ & $2.0(1.4-2.7)$ & $0.0(-)$ \\
\hline While waiting for the result & $16.3(14.8-18.0)$ & $16.0(14.5-17.7)$ & $28.6(16.6-44.6)$ \\
\hline More concerned after participation & $0.6(0.3-1.0)$ & $0.3(0.2-0.7)$ & $11.9(4.9-26.4)$ \\
\hline Concerns induced twice & $7.5(6.5-8.8)$ & $7.5(6.4-8.7)$ & $9.5(3.5-23.6)$ \\
\hline At the receiving of the invitation and while waiting for the result & $6.6(5.6-7.7)$ & $6.6(5.6-7,7)$ & $7.1(2.2-20.7)$ \\
\hline At the receiving of the invitation and more concerned after participation & $0.2(0.1-0.5)$ & $0.2(0.1-0.5)$ & $0.0(-)$ \\
\hline While waiting for the result and more concerned after participation & $0.8(0.5-1.3)$ & $0.7(0.4-1.2)$ & $2.4(0.3-16.2)$ \\
\hline Screening induced concerns at all points & $1.1(0.7-1.6)$ & $0.8(0.5-1.3)$ & $11.9(4.9-26.3)$ \\
\hline
\end{tabular}

Numbers in italic are subdivisions of the above non italic proportions

Pearson's chi-square test for difference between level of concern in women with positive screening test vs. negative screening test was $<0.001$ for all items

aNo screening induced concerns refers to all women answering "To a minor extent" or "Not at all" in items on concerns at the receiving of the invitation and

while waiting for the result and answering "Nothing has changed" or "Less worried" in the item on concerns after participation

reported more screening-induced concerns than women with negative screening results. However, concerns that arose while waiting for the results were most commonly reported, regardless of the screening result. Surprisingly, almost two out of five women with positive screening results reported no screening-induced concerns.

\section{Strengths and limitations}

One strength of this study is that participants were invited from the complete list of women receiving the results of their breast cancer screening examination during the study period. Thus, the women who were randomly selected from the five screening units are highly representative of the target population. Additionally, the data regarding demographic characteristics had very few missing values due to the completeness of the Danish CRN system. One potential problem could be that the data from Statistics Denmark was from 2012, while the survey was conducted in 2013. However, ethnicity classification cannot change between years, and changes in education and marital status are expected to be negligible. Only $0.6 \%$ of women in this age group were getting divorced in 2013 [25]. Thus, the retrieved demographic data are expected to be very valid and of high quality. Our study benefitted from the opportunity to adjust for confounding of parameters obtained from high-validity registers.

With regards to the data collected by questionnaire, selection bias is one potential weakness. The survey response rate was fairly high (71.3\%), but the respondents and the non-respondents significantly differed in age, ethnicity, and marital status. The groups that were best represented in the survey (the oldest age groups, Danish women, and married/ cohabitating women) tended to show higher satisfaction than other groups, suggesting that the general satisfaction in the population may be lower than the overall rate in our study. Furthermore, all information was collected retrospectively, opening up the possibility of recall bias, which may differ between women with negative and positive screening results. However, sensitivity analyses showed that omitting women with positive screening results did not alter the associations. Recall bias may also especially apply to questions about emotions related to the screening invitation that was received up to 2 months earlier.

Finally, as this study was embedded within the ongoing quality assurance program in our region, we did not measure satisfaction or concerns using existing scales. However, all questions were chosen based on literature review, and subsequently underwent an ad hoc procedure within the target population to test for face-validity, as described. Overall, we believe that this study has adequate internal validity, and that the results can be generalized at least to women participating in the Danish breast cancer screening program, and likely also to similarly managed programs in other countries.

\section{Interpretation of results}

Previous studies in countries with free populationbased breast cancer screening programs have reported high levels of general satisfaction [21, 26, 27]. Compared with a previous satisfaction survey in the CDR in 2010 [28], our present results showed an even higher level of general satisfaction. This is somewhat surprising as the process in the CDR has been highly streamlined, with only $5 \mathrm{~min}$ allocated to each examination. Our findings indicate that women accept this effective organization, or may even prefer it over a more timeconsuming procedure. However, the efficiency of this procedure may be at the expense of personal considerations for the women's modesty, causing some women to be less satisfied. 
Table 4 Associations between satisfaction and background data and remaining outcomes

\begin{tabular}{|c|c|c|}
\hline & Unadjusted PR (Cl) & Adjusted $^{\text {a }}$ PR $(\mathrm{Cl})$ \\
\hline \multicolumn{3}{|l|}{ Age } \\
\hline $50-54$ years & 1 (ref) & 1 (ref) \\
\hline $55-59$ years & $0.93(0.89-0.98)^{\ddagger}$ & $0.94(0.90-0.99)^{\ddagger}$ \\
\hline $60-64$ years & $0.93(0.88-0.98)^{\ddagger}$ & $0.92(0.87-0.97)^{\ddagger}$ \\
\hline $65-70$ years & $0.94(0.86-1.03)$ & $0.94(0.86-1.04)$ \\
\hline \multicolumn{3}{|l|}{ Marital status } \\
\hline Married/Cohabitant & 1 (ref) & 1 (ref) \\
\hline Single & $1.03(0.96-1.11)$ & $1.03(0.96-1.11)$ \\
\hline \multicolumn{3}{|l|}{ Ethnicity } \\
\hline Danish & 1 (ref) & 1 (ref) \\
\hline Immigrant (Western) & $1.08(0.91-1.27)$ & $1.03(0.85-1.25)$ \\
\hline Immigrant (non-western) & $0.71(0.56-0.90)^{\ddagger}$ & $0.75(0.58-0.97)^{\ddagger}$ \\
\hline \multicolumn{3}{|l|}{ Education } \\
\hline$\leq 10$ years & $0.92(0.89-0.96)$ & $0.93(0.90-0.96)$ \\
\hline $11-15$ years & 1 (ref) & 1 (ref) \\
\hline$>15$ years & $0.96(0.92-1.01)$ & $0.96(0.91-1.01)$ \\
\hline \multicolumn{3}{|l|}{ Discomfort } \\
\hline \multicolumn{3}{|l|}{ Pain (2) } \\
\hline No & 1 (ref) & 1 (ref) \\
\hline Yes & $0.83(0.75-0.92)^{\ddagger}$ & $0.82(0.74-0.91)^{\ddagger}$ \\
\hline \multicolumn{3}{|c|}{ Limits of modesty exceeded (2) } \\
\hline No & 1 (ref) & 1 (ref) \\
\hline Yes & $0.79(0.70-0.89)$ & $0.79(0.71-0.88)$ \\
\hline \multicolumn{3}{|l|}{ Feeling obliged (2) } \\
\hline No & 1 (ref) & 1 (ref) \\
\hline Yes & $0.94(0.91-0.98)^{\ddagger}$ & $0.96(0.92-0.99)^{\ddagger}$ \\
\hline \multicolumn{3}{|l|}{ Being concerned } \\
\hline \multicolumn{3}{|l|}{ At invitation (2) } \\
\hline No & 1 (ref) & 1 (ref) \\
\hline Yes & $0.66(0.51-0.86)^{\ddagger}$ & $0.67(0.52-0.85)^{\ddagger}$ \\
\hline \multicolumn{3}{|l|}{ Waiting for result(2) } \\
\hline No & 1 (ref) & 1 (ref) \\
\hline Yes & $0.84(0.77-0.92)^{\ddagger}$ & $0.85(0.78-0.93)^{\ddagger}$ \\
\hline \multicolumn{3}{|c|}{ More concerns after screening (3) } \\
\hline No & 1 (ref) & 1 (ref) \\
\hline Yes & $0.71(0.50-0.99)^{\ddagger}$ & $0.70(0.50-1.00)^{\ddagger}$ \\
\hline \multicolumn{3}{|l|}{ Concerns at any time } \\
\hline No & 1 (ref) & 1 (ref) \\
\hline Yes & $0.83(0.76-0.91)$ & $0.84(0.77-0.91)$ \\
\hline \multicolumn{3}{|l|}{ Screening test } \\
\hline Positive & 1 (ref) & 1 (ref) \\
\hline Negative & $1.04(0.87-1.26)$ & $1.02(0.83-1.26)$ \\
\hline
\end{tabular}

Associations between socio-demography, discomfort, obligations, concerns and being highly satisfied with breast cancer screening (1)
Prevalence Ratio (PR) with 95\% confidence interval (Cl) Numbers in bold indicate statistically significant results

${ }^{\ddagger} P$-value $<0.05$

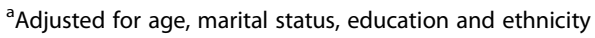

(1) Highly satisfied is defined as women answering "Excellent" in the question "What was your overall impression of the entire mammography screening process?" Less satisfied is defined as women answering either "Fine", "Poor", or "Really poor" in the same question

(2) Yes is defined as women answering either "to a great extent" or "to some extent", while No is defined as women answering "to a minor extent" or "not at all

(3) Yes is defined as women answering "more worried", while No is defined as women answering "nothing has changed" or "less worried"

Although satisfaction was very high in this study, we observed a U-shaped tendency according to educational level-with lower satisfaction among women with lower or higher educational levels and greater satisfaction among those with a medium educational level. Jensen et al. observed a similar association between educational level and screening participation in the CDR-with loweducational and high-educational women showing PR of nonparticipation of 1.1 and 1.15, respectively [29]. Together, these findings suggest that medium-educated women participate more and are more satisfied with the screening program compared to other women in the CDR. Studies on information needs and general perception of the screening offer in lower and higher educational level citizens are needed in order to know how to reach the different sub-groups in a screening setting.

In previous studies, pain during screening has been reported by $8.8 \%$ [30] and 6\% [31] of women, which is less than the $18 \%$ observed in our study. This difference could be due to different methods of measurement, which cannot be compared due to limited information in the publications. In our study, pain during screening was associated with lower degree of satisfaction. Accordingly, Almog et al. previously reported a RR of 1.5 for being satisfied among participants who experienced no discomfort compared to those feeling the most discomfort [21]. Importantly, improvements in techniques should focus on ensuring little or no pain in the breast cancer screening experience, without compromising mammogram quality.

To our knowledge, no prior study has estimated how many women feel obliged to participate in breast cancer screening, or whether feeling obliged to participate is associated with satisfaction or continued participation. Here we found that half of the participants felt obliged to some or a great extent to participate in breast cancer screening, mainly for reasons categorized as their own expectations or organizational aspects. It has been argued that most people are authoritarianists and want to preserve their health, and would therefore feel guilty about not participating in an examination aimed at preserving ones health when invited by letter with a pre-booked appointment [13]. Our results indicated that women who felt obliged to 
participate were primarily driven by their wish to preserve their health and to a lesser extend by the fact that the invitation included a pre-booked appointment. This suggests that it is not as much the organizational aspects of the screening program as it is the offer to participate itself that makes women feel obliged to participate, and it could be that the main pressure comes from a wish to preserve health with the pre-booked appointment only adding up on that feeling. Women who felt obliged to participate were slightly less satisfied than women who did not feel obliged to participate. Since patient satisfaction is based on different factors of perceived quality [20] it could also be hypothesized that a citizen taking up screening because of obligations to others (family/friends/society) might experience lower levels of satisfaction. However, further research is needed to examine why and how some women feel obliged to participate and how it affects them and their experience with breast cancer screening.

A New Zealand study reported that $11 \%$ of women participating in breast cancer screening were worried while waiting for the screening examination, $18 \%$ while waiting for the results, and $1 \%$ were more worried after completing the screening [32]. Women in our study experienced somewhat more screening-induced concerns than women in the New Zealand study, but the tendencies were similar. Women reported that they predominantly experienced concerns while waiting for their results, underlining the importance of quickly delivering the screening results to participating women to minimize their concerns.

In a previous study, a substantial proportion of women with false-positive screening results experienced mammography-related anxiety (47\%) or cancer-related worries (41\%) 3 months later; however, these worries did not influence subsequent screening adherence [33]. Another study reported that compared to women with normal findings, those with false-positive screening results consistently experienced greater negative psychological consequences at 3 months and 3 years later [34]. Our study was not designed to measure long-term consequences of false-positive screening results. However, the previously reported figures seem rather large compared to our present finding that $25.6 \%$ of women with a positive screening result experienced more concerns a few weeks after participating in the screening compared to before the screening. Additional research could help to fully understand the extent of concerns and anxiety among women participating in breast cancer screening.

Peipins et al. found that satisfied women tend to paticipate more in future screening examinations [9]. We did not explore this in our study, but we do know from a previous satisfaction survey in our region, that the general satisfaction is also high 3 years earlier [28]. Thus high continuing satisfaction may be one reason for a continuing high participation rate above $80 \%$ in our region.

\section{Conclusions}

Overall, satisfaction was very high among women participating in breast cancer screening in the CDR. Lower satisfaction was reported among women who experienced discomfort, obligations, or concerns and among nonwestern immigrants. The present results indicate that concerns regarding breast cancer were introduced only among a minimum of participating women with normal screening results, and to a lesser degree in women with positive screening results as compared to previous studies. Further, almost half of the women stated that they felt obliged to participate, which calls for further research in order to understand its significance and implications.

It appears that a continuing focus on high service in breast cancer screening is important for achieving the highest benefit from the program. This includes initiatives to employ the least painful techniques, to respect the patients' modesty as much as possible, to deliver fast screening results and thus minimize concerns among women awaiting results, and to design interventions with different minorities in mind.

\section{Additional file}

Additional file 1: Questionnaire. (PDF $107 \mathrm{~kb}$ )

\section{Abbreviations}

CDR: Central Denmark Region; Cl: Confidence interval; CRN: Civil registration number; OR: Odds ratio; PR: Prevalence ratio; RR: Relative risk

\section{Acknowledgements}

Anne Marie Schak Jensen, MPH, contributed to the data management and preliminary analyses.

\section{Funding}

This research received no specific grant from any funding agency in the public, commercial, or nonprofit sectors. Expenses were covered by the Department of Public Health Programmes as part of continued quality improvement.

Availability of data and materials

According to Danish law; data can only be made available by contacting the authors. Hence data is not available for the general public, other than by contacting the authors.

Authors' contributions

All authors contributed to the study design and the questionnaire preparation and creation. PBN and DBS led the data acquisition and assembling of the primary data. PG and MBL obtained data on demographic characteristics from Statistics Denmark. PG, MBL, and BSA planned the statistical analyses. PG conducted the statistical analyses and produced the first draft of the manuscript, which all authors subsequently contributed to. All authors read and approved the final manuscript.

\section{Ethics approval and consent to participate}

In accordance with Danish law, the study was approved by the Danish Data Protection Agency (Journal Number: 2007-58-0010/Case number: 1-16-02-423-13). Participants consented to participate in the study by completing the questionnaire. 


\section{Consent for publication}

Not applicable.

\section{Competing interests}

The authors declare that they have no competing interests.

\section{Publisher's Note}

Springer Nature remains neutral with regard to jurisdictional claims in published maps and institutional affiliations.

\section{Author details}

'Department of Public Health Programmes, Regional Hospital Randers, Skovlyvej 15, DK-8930 Randers NØ, Denmark. ²DEACTUM, Central Denmark Region Aarhus, Olof Palmes Alle 15, DK 8200 Aarhus N, Denmark.

Received: 22 June 2016 Accepted: 6 July 2017

Published online: 14 July 2017

\section{References}

1. DeSantis CE, Bray F, Ferlay J, Lortet-Tieulent J, Anderson BO, Jemal A. International variation in female breast cancer incidence and mortality rates. Cancer Epidemiol Biomark Prev. 2015:24(10):1495-506.

2. Torring ML, Frydenberg M, Hansen RP, Olesen F, Vedsted P. Evidence of increasing mortality with longer diagnostic intervals for five common cancers: a cohort study in primary care. Eur J Cancer. 2013;49(9):2187-98.

3. Gotzsche PC, Nielsen M. Screening for breast cancer with mammography. Cochrane Database Syst Rev. 2009;4:CD001877. doi:10.1002/14651858.CD001877.

4. Independent UK Panel on Breast Cancer Screening. The benefits and harms of breast cancer screening: an independent review. Lancet. 2012;380(9855):1778-86.

5. OECD. Health at a glance 2011. Organisation for Economic Co-operation and Development; 2011. Available in English at http://www.oecd.org/els/ health-systems/49105858.pdf

6. Brodersen J, Jorgensen KJ, Gotzsche PC. The benefits and harms of screening for cancer with a focus on breast screening. Pol Arch Med Wewn. 2010;120(3):89-94.

7. Duffy SW, Tabar L, Chen HH, Holmqvist M, Yen MF, Abdsalah S, et al. The impact of organized mammography service screening on breast carcinoma mortality in seven Swedish counties. Cancer. 2002;95(3):458-69.

8. Breast Screening Frequency Trial Group. The frequency of breast cancer screening: results from the UKCCCR randomised trial. United Kingdom Coordinating Committee on Cancer Research. Eur J Cancer. 2002;38(11):1458-64.

9. Peipins LA, Shapiro JA, Bobo JK, Berkowitz Z. Impact of women's experiences during mammography on adherence to rescreening (United States). Cancer Causes Control. 2006;17(4):439-47.

10. Tang TS, Patterson SK, Roubidoux MA, Duan L. Women's mammography experience and its impact on screening adherence. Psychooncology. 2009i 18(7):727-34.

11. Vejborg I, Mikkelsen E, Garne JP, Bak M, Lernevall A, Mogensen NB, et al. Mammography screening in Denmark. Dan Med Bull. 2011;58(6):C4287.

12. The Danish Database for Quality in Mammography screening (DKMS). Annual report 2016 [Danish]; 2016. p. 7. Available in Danish at https://www. sundhed.dk/sundhedsfaglig/kvalitet/kliniske-kvalitetsdatabaser/screening/ brystkraeftscreening-dkms/.

13. Ploug T, Holm S, Brodersen J. To nudge or not to nudge: cancer screening programmes and the limits of libertarian paternalism. J Epidemiol Community Health. 2012;66(12):1193-6.

14. Statistics Denmark. Population in Denmark and the Central Denmark region, October 1st 2013 [available in English]. 2016; Available at: www. statistikbanken.dk. Accessed 20 Apr 2016.

15. Jensen LF, Pedersen AF, Andersen B, Fenger-Gron M, Vedsted P. Distance to screening site and non-participation in screening for breast cancer: a population-based study. J Public Health (Oxf). 2014;36(2):292-9.

16. Pedersen CB. The Danish civil registration system. Scand J Public Health. 2011;39(7 Suppl):22-5.

17. Center for Patient Experience and Evaluation, DEFACTUM. [LUP: the national assessment of patient experiences] in Danish. 2016; Available at: http:// patientoplevelser.dk/lup. Accessed 3 May 2016.

18. Statistics Denmark. The division of research services, statistics Denmark [available in English]. 2016; Available at: www.dst.dk. Accessed 25 Apr 2016.
19. UNESCO. ISCED: International Standard Classification of Education. 2014; Available at: http://uis.unesco.org/sites/default/files/documents/ international-standard-classification-of-education-isced-2011-en.pdf. Accessed 12 Jul 2017

20. Mohamed B, Azizan NA. Perceived service quality's effect on patient satisfaction and behavioural compliance. Int J Health Care Qual Assur. 2015;28(3):300-14.

21. Almog R, Hagoel L, Tamir A, Barnett O, Rennert G. Quality control in a National Program for the early detection of breast cancer: women's satisfaction with the mammography process. Womens Health Issues. 2008;18(2):110-7.

22. Sider RC, Clements CD. Patients' ethical obligation for their health. J Med Ethics. 1984;10(3):138-42.

23. Zou G. A modified poisson regression approach to prospective studies with binary data. Am J Epidemiol. 2004;159(7):702-6.

24. Barros AJ, Hirakata VN. Alternatives for logistic regression in cross-sectiona studies: an empirical comparison of models that directly estimate the prevalence ratio. BMC Med Res Methodol. 2003;3:21.

25. Statistics Denmark. Population and divorces in Denmark, 2013; STATBANK Denmark, Statistics Denmark [Available in English]. 2015; Available at: www. statistikbanken.dk. Accessed 11 Dec 2015.

26. Saladie F, Poblet C, Sirgo A, Galceran J. Women's satisfaction with the breast cancer screening programme in Tarragona, Spain. Breast J. 2008;14(3):315-6.

27. Han MA, Jun JK, Choi KS, Park EC, Lee HY. Satisfaction in the National Cancer Screening Program for breast cancer with and without clinical breast examination. Asian Pac J Cancer Prev. 2012;13(1):63-7.

28. Public Health and Quality Improvement. Screening for breast cancer satisfaction in the breast cancer screening programme in the Central Denmark Region 2010-2013 [Danish]. 2014. [Available in Danish at http:// www.defactum.dk/

29. Jensen LF, Pedersen AF, Andersen B, Vedsted P. Identifying specific nonattending groups in breast cancer screening-population-based registry study of participation and socio-demography. BMC Cancer. 2012;12:518. doi: 10.1186/1471-2407-12-518

30. Brotherton J, Taylor R, Ivanov O, Tewson R, Page A. "It's much easier than going to the dentist": high levels of satisfaction in a mammography screening program. Aust N Z J Public Health. 2007:31(4):353-9.

31. Rutter DR, Calnan M, Vaile MS, Field S, Wade KA. Discomfort and pain during mammography: description, prediction, and prevention. BMJ. 1992 305(6851):443-5

32. Brunton M, Jordan C, Campbell I. Anxiety before, during, and after participation in a population-based screening mammography programme in Waikato Province, New Zealand. N Z Med J. 2005;118(1209):U1299.

33. Lerman C, Trock B, Rimer BK, Boyce A, Jepson C, Engstrom PF. Psychological and behavioral implications of abnormal mammograms. Ann Intern Med. 1991:114(8):657-61.

34. Brodersen J, Siersma VD. Long-term psychosocial consequences of falsepositive screening mammography. Ann Fam Med. 2013;11(2):106-15.

\section{Submit your next manuscript to BioMed Central and we will help you at every step:}

- We accept pre-submission inquiries

- Our selector tool helps you to find the most relevant journal

- We provide round the clock customer support

- Convenient online submission

- Thorough peer review

- Inclusion in PubMed and all major indexing services

- Maximum visibility for your research

Submit your manuscript at www.biomedcentral.com/submit
C) BioMed Central 